\title{
OUTROS TEMAS \\ COMBATE AO SEXISMO EM LIVROS DIDÁTICOS: CONSTRUÇÃO DA AGENDA E SUA CRÍTICA
}

FÚLVIA ROSEMBERG

Professora do Programa de Psicologia Social, da Pontifícia Universidade Católica de São Paulo (Núcleo de Estudos de Gênero, Raça e Idade);

Pesquisadora do Departamento de Pesquisas Educacionais da Fundação Carlos Chagas

(Programa Internacional de Bolsas de Pós-Graduação da Fundação Ford) frosenberg@fcc.org.br

\section{NEIDE CARDOSO DE MOURA}

Professora dos Cursos de Pedagogia da Universidade São Judas Tadeu e do Centro Universitário Fieo professoraneide@gmail.com

\section{PAULO VINÍCIUS BAPTISTA SILVA}

Professor do Núcleo de Estudos Afro-Brasileiros, da Universidade Federal do Paraná paulovsilva@uol.com.br

\section{RESUMO}

O artigo tem por objetivo descrever e problematizar a construção da agenda sobre "sexismo no livro didático" em cenário internacional e nacional. Para tanto, efetua uma revisão crítica da literatura desde a década de 1960 até a contemporaneidade, dando especial ênfase a permanências e mudanças, bem como a tensões detectadas na implementação de políticas que visam o combate ao "sexismo" nos livros didáticos.

LIVROS DIDÁTICOS - BIBLIOGRAFIA - PROGRAMA NACIONAL DO LIVRO DIDÁTICO SEXISMO

\section{ABSTRACT}

FIGHTING SEXISM IN TEXTBOOKS: AGENDA CONSTRUCTION AND ITS CRITICS. The article aims to describe the creation of an agenda on "sexism in textbooks" on the international and national levels. To accomplish this, it includes a critical review of the literature from the 1960's to the present placing special emphasis on the changes and what remains the same, as well as the tensions detected in the implementation of policies aiming at fighting "sexism" in textbooks. TEXTBOOKS - BIBLIOGRAPHY - BRAZILIAN NATIONAL TEXTBOOK PROGRAM - SEXISM 
É antiga a preocupação de adultos com o conteúdo de livros e de outros suportes, destinados à formação das jovens gerações. Choppin (2004) destaca a importância atribuída à "função ideológica e cultural" dos livros didáticos - LD -, "a partir do século XIX, com a constituição dos estados nacionais e com o desenvolvimento, nesse contexto, dos principais sistemas educativos". Instrumento privilegiado de construção de identidades, "geralmente ele é reconhecido, assim como a moeda e a bandeira, como um símbolo da soberania nacional e, nesse sentido, assume um importante papel político" (p.553).

É dessa ótica que se fizeram as primeiras revisões internacionais dos livros escolares visando à eliminação de preconceitos xenofóbicos após a Primeira Guerra Mundial. Assim, educadores(as)' e políticos, além de criticarem imagens "errôneas" sobre os "inimigos" veiculadas pelos LD nacionais, tomaram uma série de iniciativas no seio da Sociedade das Nações que redundaram na elaboração e assinatura, em 1937, de uma Declaração sobre Ensino da História e Revisão dos Livros Didáticos (Pingel, 1999). É nesse período (1933) que localizamos talvez a primeira ação de normatização do conteúdo do LD pelo Estado brasileiro. Trata-se do convênio firmado entre Brasil, Argentina e México para que se expurgassem dos textos de ensino aqueles "tópicos que recordam paixões pretéritas” (Hollanda, 1957). Para tanto, foi criada em 1938 , no Ministério das Relações Exteriores, a Comissão Brasileira Revisora de Textos de História e Geografia, precursora da Comissão Nacional do Livro Didático, iniciando, então, a longa e descontínua história da política pública brasileira do LD que tem incluído a análise crítica de seu conteúdo e que se traduz, desde os anos 1980, no Programa Nacional do Livro Didático - PNLD.

A análise das imagens de "mulher", "relações de gênero", "sexismo", "estereótipos sexuais ou de gênero" nos LD, que se inicia nas décadas de 1960-1970, toma o LD seja como "informante" ou como "construtor" de mentalidades, no caso dos "papéis sexuais" ou das "identidades de gênero" conforme o período considerado. Porém, esta produção não se originou de grupos de pesquisa ou de educadores interessados primeiro nos LD: originou

I. A partir deste ponto, e para aliviar o texto, abandonaremos a fórmula o(a), usando de preferência o genérico masculino, desde que a precisão do sentido não requeira o uso dos dois gêneros gramaticais. 
-se e se fixa como uma produção de acadêmicas e ativistas feministas que estão demarcando um problema social - a denúncia da "educação diferenciada" de meninas e meninos, o viés "sexista" na educação - e construindo agendas e estratégias políticas de combate à discriminação das mulheres.

Essa marca de origem impregnou ambas as áreas de pesquisa e intervenção: o tema "estereótipos sexuais" não adentrou a grande área de pesquisa sobre LD, da mesma forma que a área de estudos sobre LD pouca entrada tem tido na produção acadêmica sobre "estereótipos sexuais". Tal guetização tem consequências, a nosso ver, no impacto que essa mobilização tem tido nas propostas de alteração do conteúdo dos LD, como discutiremos adiante.

Neste artigo elaboramos um estado da arte sobre o tema em cenários internacional e brasileiro. Nosso foco é discutir as vicissitudes na construção e implementação da agenda acadêmica e política de combate ao sexismo nos LD.

\section{CONSTRUÇÃO E ENFRENTAMENTO DE UM PROBLEMA SOCIAL}

É sem dúvida a década de 1970, com a institucionalização do novo movimento de mulheres, inclusive na academia, que inaugura e enquadra os enfoques desse novo problema social: a superação da educação diferenciada de homens e mulheres na escola e da veiculação de estereótipos sexuais no currículo escolar e nos LD.

A bibliografia menciona alguns textos anteriores a 1970: o de Child, Potter e Levine (1946) que já constatava sobrerrepresentação de personagens masculinos em LD norte-americanos; a menção no volume 2 do Segundo sexo de Simone de Beauvoir (1960) à passividade feminina na literatura infantil; as teses de Mollo (1969) e Rosemberg (1969), na França, sobre LD e literatura infantil e a tese de Zimet (1968) sobre papéis sexuais em quatrocentos anos ( 600 a 1960) de história norte-americana de livros de leitura.

Os Estados Unidos oferecem um posto privilegiado para observar a mudança de paradigma no enfoque da educação no processo de socialização de papéis sexuais, na virada da década de 1960 para a de 1970. Em 1968, Zimet assinalava que os LD que analisou transmitiam imagens de papéis sexuais pouco diferenciados, menos marcados que os efetivamente vigentes na sociedade norte-americana e que isto era prejudicial, especialmente aos meninos, que apresentavam piores resultados em leitura. $\bigcirc$ ideal, portanto, seriam LD 
que apresentassem modelos de papéis sexuais demarcados. Zimet (1968) era ainda defensora do ideal educacional que se instalou no Ocidente a partir de Rousseau: a diferenciação na socialização de padrões de conduta de homens e de mulheres como uma das metas da educação. E só nos anos 1970 que a educação específica (ou diferenciada) para cada sexo foi problematizada pelo feminismo (Nielsen, Bronwyn, 2007), denunciando-se os logros da coeducação escolar que, apesar de sua extensão, não cumpria o ideal de uma educação igualitária para homens e mulheres.

Apenas três anos separam a tese de Zimet (1968) da publicação de um dos ícones da época, a coletânea norte-americana Woman in sexist society: studies in power and powerlessness (Gornick, Moran, 1971). Nesse livro, Marjorie B. U'Ren (professora em Berkley e membro, na época, da National Organization for Women - Now - assina o artigo "The image of woman in textbooks", denunciando o fato de homens e mulheres não receberem a mesma educação no sistema educacional.

Sua educação reflete os papéis que a sociedade espera que desempenhem. Nossa sociedade ensina ao homem, e não à mulher, que deve realizar, progredir, criar. Esta deferência dirigida ao homem é particularmente evidente nos livros escolares usados por crianças na escola primária. (p.3|8)

Baseada na análise de 30 livros adotados e recomendados para serem usados no estado da Califórnia, observou, além de sobrerrepresentação masculina (75\% dos personagens principais), uma imagem feminina acantonada no espaço doméstico e desvalorizada em atividades econômicas. Sua aspiração era que os livros oferecessem diversidade de modelos para que as meninas pudessem escolher. Diferente da ênfase de Zimet (1968) nos meninos, agora as meninas passam a ocupar o proscênio. Instala-se, o que Blumberg (2007) denomina primeira geração de estudos sobre estereótipos sexuais nos LD e que se irradia para todos os continentes.

A produção norte-americana, acadêmica e ativista, expande-se a tal ponto na década de 1970 que a revisão bibliográfica de Kingston e Lovelace, publicada em 1978, já identificara 78 artigos publicados. Desta produção norte-americana inicial, destacamos a reiteração dos resultados na direção apontada por U'Ren ( 197 I), o enquadre teórico-político do feminismo liberal, 
a diversidade de atores envolvidos na publicização e enfrentamento desse problema social (academia, movimento feminista, professores, pais, Estado, editoras) e das estratégias preconizadas para superação de estereótipos: alteração de legislação, audiência pública, publicações, constituição de lobby, elaboração de código de autorregulação de editoras, difusão de bibliografias e guias de livros não sexistas. Assim, feministas norte-americanas criaram uma editora já em 1970 (a Feminist Press), revistas prestigiadas (como o American Journal of Sociology) abriram espaço para o tema (Weitzman et al., 1972) e editoras destacadas, como a McGraw Hill, criaram, desde 1972, guias de orientação para elaboração de material não sexista destinados aos seus colaboradores.

Nessa produção, o foco recai sobretudo nas personagens mulheres, os termos-conceitos priorizados são "estereótipos de sexo" ou "sexismo" (neologismo criado na época absorvendo o conceito de racismo), usam-se procedimentos de análise de conteúdo e considera-se apenas incidentalmente a perspectiva racial e geracional. Poucas pesquisas na época analisam a apreensão desses conteúdos pelos destinatários dos LD, apesar de estudos e intervenções pressuporem uma relação de causa e efeito (geralmente linear e imediata) entre conteúdo e papéis sexuais (Kingston, Lovelace, 1978). Trata-se de uma produção de denúncia e cujo volume não foi superado nas décadas posteriores. Com efeito, pesquisa que realizamos na base de dados Education Resources Information Center - Eric -, usando o descritor sex-stereotypes - textbooks no período 1966 até 2008, localizou 249 entradas, 57\% delas anteriores à década de 1980.

Em cenário europeu, duas publicações italianas do início dos anos 1970 merecem destaque pela difusão e impacto no enquadramento do tema: o livro de Elena Gianini Belotti, Dalla parte delle bambine (1973) e o de Mariza Bonazzi e Umberto Eco, I pampini bugiardi, de 1975 (publicação no Brasil em 1980).

Baudelot e Establet (2007, p.7), revisitando o livro de Belotti, destacam sua extraordinária penetração na Europa e, acrescentamos, na América Latina. Ao longo do livro, Belotti analisa a "influência dos condicionamentos sociais na formação do papel feminino desde a pequena infância". Nesse processo de denúncia da socialização diferenciada, o foco recai sobre a menina, o modelo teórico é o condicionamento social, sendo que as construções de identidade de sexo e desigualdade de sexo são geralmente confundidas. Em dois capítulos, 
Belotti (1 973) trata de LD e literatura infantil, divulgando, além das experiências europeias, o ativismo de feministas norte-americanas ${ }^{2}$.

O livro de Bonazzi e Eco (1980), especialmente influente na América Latina, contribuiu para a divulgação do tema e do método de investigaçãodenúncia, por vezes denominado método "qualitativo", e que consiste no pinçamento de exemplos que ilustram as situações que se quer denunciar (Negrão, Amado, 1989). Tais pesquisas, relativamente frequentes no Brasil nos anos 1980, foram duramente criticadas por estudiosos do LD (Freitag, Motta, Wanderly, 1987), gerando, até certo ponto, resistência de integração do tema "sexismo no LD" e de outros recortes de análise ideológica na grande área e uma visão simplificadora da crítica feminista.

Na segunda metade dos anos 1970, a bibliografia já se avolumava em cenário internacional, inclusive latino-americano: Argentina (Prado, 1980), Brasil (Rosemberg, 1975), Peru (Boggio et al., I 973), Venezuela (Calero et al., 1977). Em 1977, a Conferência Regional sobre a Integración de la Mujer en el Desarrollo Económico y Social de América Latina já propunha, entre outras ações, modificar "os textos de ensino de modo a que respondam às atividades produtivas e à vida cotidiana das mulheres das áreas rurais e das zonas urbanas marginalizadas" (Lozano, 1984, p. 129).

Notável na produção internacional é a consistência dos resultados (Blumberg, 2007): sobrerrepresentação sistemática dos homens (adultos e crianças) enquanto personagens tratados como referentes universais; componentes estereotipados na caracterização de personagens femininas adultas e infantis, humanas ou antropomorfizadas, no sentido de passividade, bondade, cuidado, domesticidade, atributos mais associados ao feminino e atividade, trabalho profissional, descoberta como atributos mais associados ao masculino. Apesar de os resultados apontarem sobretudo tendências, o estilo combativo e os próprios conceitos usados (como estereótipo latente) enfatizaram interpretações binárias e que transparecem em títulos de algumas publicações -

2. Becchi e Julia (1998, p.388), em sua síntese histórica sobre a infância no século XX, destacam, entre os novos perfis de criança que foram surgindo, o da menina. "Foi necessário atingir uma época muito recente para ver surgir reflexões que partem de uma perspectiva da paridade entre meninas e meninos e procuram nela identificar um objeto específico do social. $O$ livro de Elena Gianni Belotti "é considerado uma das principais etapas desta abordagem que modifica não apenas o objeto da análise mas as modalidades de seu estudo". 
Papa lit, maman coud..., de Decroeux-Masson (1979) -, ou nos qualificativos usados, como por exemplo, "a invisibilidade das mulheres", como sinônimo de sua sub-representação. Nota-se, então, o uso de uma retórica que busca o convencimento, como é frequente na delimitação e demarcação de novos problemas sociais que competem para integrar a agenda de prioridades em políticas sociais (Hilgartner, Bosk, 1988).

As conferências internacionais da mulher, das décadas de 1970 e 1980 (México, Copenhaguem e Nairobi), legitimaram e difundiram o tema que começou a contar com o apoio de novos atores sociais: as organizações multilaterais e fundações internacionais. Particularmente importante foi um dos desdobramentos da Conferência de Copenhague, de 1980, quando a Unesco encomendou a Andrée Michel, socióloga, pesquisadora do Centre National de Recherche Scientifique - CNRS - da França, uma síntese de pesquisas que financiara alguns anos antes em sete países: China, França, Kuait, Noruega, Peru, República Socialista Soviética da Ucrânia e Zâmbia. Publicado originalmente em francês em 1986, o texto foi traduzido em português (1989), espanhol e inglês, tendo orientado estudos nacionais posteriores, como os da América Central.

Desse texto de Andrée Michel (1989) destacamos a proximidade entre os resultados encontrados em países distintos do ponto de vista econômico, político, cultural e educacional, inclusive quanto ao acesso das mulheres, e o conceito de estereótipo manifesto e latente que passou a orientar grades de análise de conteúdo, bem como propostas de alteração dos LD. Para Michel "a primeira manifestação do sexismo está no fato de se negar a realidade social e a diversidade de situações, o que chega até a dar uma apresentação caricatural das imagens e dos papéis masculinos e femininos" (1989, p.49), o que seria a expressão de estereótipo latente. Assim, a expectativa passou a ser, para alguns, que o LD propusesse novos modelos de masculino e feminino, mesmo que distantes dos vigentes no contexto social. Tal expectativa percorreu as décadas posteriores.

Defendida (e não problematizada) por diversos autores(as), tal perspectiva se constrói em terreno minado, na medida em que, mesmo quando explicitado, não há unanimidade sobre o ponto de chegada, pois as várias tendências teóricas e políticas do feminismo remetem a múltiplos modelos de relações de gênero. Apesar da ausência de estudos sobre os enfoques teóricos e políticos que têm embasado essa produção, dispõem-se de pistas de que o 
enfoque dominante tem sido o feminismo liberal. Por exemplo, Clark, Kulkin e Clancy (1999), analisando a produção norte-americana sobre livros para crianças, assinalam a penetração do paradigma feminista liberal introduzido pelo estudo pioneiro de Weitzman et al. (1972). Sustentam sua avaliação apontando a ênfase desses estudos na igualdade de oportunidades e na realização individual, bem como na escassez de referências a raça, classe e idade.

Como ocorrera nos Estados Unidos, a denúncia de sexismo nos LD na Europa, América Latina e Caribe, África e Ásia tem sido acompanhada de recomendações e ações diversificadas para sua superação: sensibilização da opinião pública, alteração da legislação, concursos e premiação de livros não sexistas, códigos de autorregulação de editoras, formação de educadores e produtores de LD, além de inúmeras publicações, seminários e encontros. Não localizamos registros de que tenha ocorrido monitoramento sistemático dessas atividades, nos moldes de estratégias usadas em pesquisa-ação, como destaca Povey (2004) para a Inglaterra, o que dificulta a construção de balanço preciso. Mesmo correndo o risco de imprecisão, destacamos alguns pontos de perpassam essa produção até 2000: a participação ativa de órgãos de Estado da mulher/condição feminina que foram criados em diferentes países nas décadas de 1970, 1980 e 1990 e que subsidiaram a realização de pesquisas ou avaliação de mudanças (Quebeque, Espanha e França ${ }^{3}$ ); a realização de estudos em conglomerados de países, como os da União Europeia (Terneu-Évrard, 1984), da África (Brugeilles, Cromer, Loch, s/d) e da América Central (Unicef, Unifem, 1990); a alteração de leis nacionais de educação que passaram a incorporar quesitos relacionados à valorização da diversidade cultural e à meta de igualdade de oportunidades nos currículos e materiais didáticos.

Tais iniciativas, múltiplas e diversificadas, não parecem, porém, obedecer a um plano sistemático, com objetivos e estratégias definidas para alterar os conteúdos especialmente no plano da criação de textos e imagens. $\bigcirc$ foco privilegiado parece ser a crítica, a denúncia.

Entre as décadas de 1990 e 2000, além da expansão territorial das pesquisas, atingindo agora a África, Ásia e ex-países socialistas, nota-se a ampliação dos recortes disciplinares e níveis de ensino dos LD analisados, das instituições

3. Dentre eles, destacamos a extensa pesquisa encomendada pelo Instituto de la Mujer da Espanha (Gimeno, 1999-2000). 
envolvidas na abertura a novos temas, como a ênfase no heterossexualismo (Temple, 2005) ou a masculinidade (Lorraine, Kimberly, 2000), a alteração da terminologia - que passou a privilegiar os termos gênero e viés de gênero -, e a entrada do referencial teórico dos estudos culturais. Além disso, o tema foi fortalecido pelo destaque dado ao gender gap na agenda internacional da educação por declarações e acordos que Estados nacionais firmaram ao longo das últimas décadas (Educação para Todos, Metas do Milênio, por exemplo).

Isso tudo provocou o ensejo de se revisitarem os LD aferindo-se o que mudou e o que permaneceu. Assim, a partir do final dos anos 1980, inicia-se o que Blumberg (2007) denomina a segunda geração de estudos sobre gender bias nos LD, agora em perspectiva diacrônica e de monitoramento. De modo geral, os estudos assinalam que ocorreu a eliminação de preconceitos explícitos, mas que persistem estereótipos de gênero sutis nos LD e que ainda há muito a caminhar para sua superação.

Dentre as múltiplas revisões, destacaremos a de Povey (2004) no Reino Unido, as latino-americanas sobre o Peru (Cabrejo, 2006) e a Costa Rica (Umaña, 2006), a francesa (Rignault, Richert, 1997) e o balanço internacional de Blumberg (2007).

No artigo "Dimensões de gênero e desigualdades na escola: o impacto das identidades", Povey (2004) dedica um tópico à análise dos materiais didático-pedagógicos. Tomando por base pesquisas anteriores, assinala que a autoridade educacional de Londres (Ilea) "de tendência social-democrata de esquerda, apoiou várias iniciativas para promover recursos didáticos não discriminatórios" (p.60), tendo sido criados, inclusive, novos materiais. Nessas iniciativas envolveram-se professores que podiam criar seus próprios materiais com subsídio oficial. A não ser pelo impacto na mídia sensacionalista e de direita, que desencadeou campanha contrária a essa intervenção - a liberdade de imprensa e a censura foram e são invocadas, também, em outros países para opor-se às ações de combate ao sexismo -, Povey (2004) confessa que "não é fácil avaliar o impacto de iniciativas como essas que não foram planejadas como pesquisa-ação". Conclui, porém, que as imagens em LD contemporâneos "parecem mais propensas a evitar vieses de gênero" (p.6I).

Da França, destacamos o relatório de autoria da deputada Simone Rignault e do senador Philippe Richert ( 1997), dirigido ao então primeiro ministro Alain Juppé, que lhes havia encomendado um balanço sobre a representação de 
mulheres e homens nos LD. Com base em uma revisão do estado da questão na França, na União Europeia e em contexto internacional, na realização de audiências públicas, que ouviram diversos atores sociais e em análise efetuada em vários LD franceses contemporâneos, os legisladores concluem que, apesar de identificarem livros não sexistas das iniciativas assumidas desde a década de 1980, estereótipos sexistas persistem, mitigados é verdade, nos LD franceses. Dentre os obstáculos para sua superação, apontam o conservadorismo da sociedade francesa, a fragmentação e interrupção das diversas iniciativas, a diluição de responsabilidades, a diversidade de atores ${ }^{4}$, além dos próprios limites inerentes à fabricação de LD: parâmetros curriculares, concorrência no mercado, custos, tempos, competências.

No Peru, Cabrejo (2006) aponta os diferentes marcos legais no plano dos acordos internacionais em educação, da nova legislação sobre educação e do Plan Igualdad de Oportunidades entre Hombres y Mujeres - PIO -, de 2000, que abrem a possibilidade da inclusão da perspectiva de gênero nas políticas educacionais, inclusive a erradiacação dos "conteúdos sexistas do ensino, favorecendo a transmissão de valores coeducativos em todas as etapas da educação" (p.90). Porém, ao efetuar uma revisão do material didático contemporâneo, nota, ao lado de algumas modificações no uso da linguagem (referência a "niños y niñas"), a persistência de estereótipos tradicionais: representação preferencial de mulheres no espaço privado, em atitudes protetoras ou de cuidado e de homens no espaço público. Dentre os obstáculos para propiciar mudanças, aponta a forma de produção dos materiais didáticos, o uso apenas retórico pelos governos dos "acordos e convênios internacionais" e o reduzido interesse do movimento feminista peruano na "transformação do sistema educativo e que, portanto, não dispõe de uma agenda para abordar este tema" (p. 106).

A análise de Umaña (2006) recorda uma série de iniciativas adotadas pelo Estado costarriquenho desde 1982, envolvendo o Ministério de Educación Pública - MEP - e outros entes estatais; a criação de uma comissão visando introduzir mudanças nos LD, que, porém, enfrentou resistências para sua implantação no próprio MEP; a ratificação da Convenção para a Erradicação

4. A diversidade de atores é apontada também por Umaña (2006). Melhor seria assinalar contradições e tensões nas agendas dos atores. 
de todas as Formas de Discriminação contra a Mulher, que não gerou ações específicas; a participação do MEP no projeto subregional Unicef/Unifem ( 1990) de análise de LD, que redundou na substituição do LD Paco y Lola devido a seu intenso conteúdo sexista e a alteração parcial de outros textos. Porém, Umaña observa que ocorreram "sérias limitações para que o MEP impulsionasse uma linguagem não sexista e erradicasse as imagens estereotipadas de gênero (...) devido à multiplicidade de atores sociais que intervêm no processo educativo" (p. I80). Mais recentemente, uma nova série de LD, Hacia el Siglo XXI, que procurou adotar linguagem, texto e ilustrações não sexistas, foi vetada pela Corte Suprema de Justiça em decorrência de recurso apresentado por editoras, pois estabelecia a obrigatoriedade de uso desses livros, o que violaria o princípio da livre competição (p. I80). Umaña (2006) conclui que o tema deixou de ser prioritário na Costa Rica.

Ritmo lento de mudanças no conteúdo dos LD também é assinalado no recente estado da arte da socióloga norte-americana Rae Lesser Blumberg (2007), encomendado pela Unesco. Apesar de não incorporá-la ou mesmo citá-la na bibliografia, trata-se de uma atualização da síntese que Andrée Michel ( 1989 ) preparara vinte anos antes. Ao destacar a segunda geração de estudos norte-americanos focalizando permanências e mudanças no conteúdo de LD aponta: prevalência de sexismo em LD mais intensa que a paridade observada nos índices de escolarização de homens e mulheres; resistência à incorporação nos LD das mudanças observadas nas vidas das mulheres; persistência do gender bias nos LD apesar dos 35 anos de esforços para sua superação; uniformidade dos componentes do gender bias no conteúdo dos LD (sobrerrepresentação masculina, uso do gênero masculino para representação da espécie, estereótipos masculinos e femininos tradicionais nas esferas ocupacional e doméstica, estereótipos tradicionais na caracterização de traços e atividades masculinas e femininas). O texto, que inclui uma série de recomendações, várias destinadas às agências de fomento, aponta a ausência de estudos que analisam o impacto do gender bias na vida/escolaridade de homens e mulheres e a necessidade de se avaliar sua intensidade.

Do conjunto de estudos que refletem sobre a lentidão das mudanças, vale destacar, ainda, o colombiano Sexismo y educación (Faur, s/d) que, entre outros, transcreve depoimentos de autores, ilustradores, assessores que assinalam dificuldades enfrentadas na prática de fabricação dos livros. Com a palavra um ilustrador que, ao lado da pressão mercadológica, assinala: 
... as pessoas desenham mais e melhor o que conhecem e sabem como desenhar. Eu conheço melhor os sapatos dos meninos; seus agasalhos, eu os conheço em detalhes. O mesmo não ocorre para as roupas das meninas: para resolver, desenham-se as meninas com saltos e acabam sendo uns saltos fora de moda que não se usam mais. (p.68)

Isso nos remete à defasagem intergeracional entre produtores adultos de LD e receptores crianças: como adultos produtores de LD (educadores, autores, ilustradores, editores, etc) podem superar, no trato com as crianças, suas vivências e experiências de quando eram crianças? Como superar a "contemporaneidade do passado" na produção de adultos destinada às crianças (Rosemberg, 1985).

Ao final dessa esquemática revisão das artes, não nos furtaremos a uma reflexão sobre algumas particularidades no tratamento do tema. Além de lamentar a ausência de registros sistemáticos das experiências internacionais, o que se reflete na dispersão das fontes, notamos alguns pontos de fragilidade nessa produção: fragmentação, isolamento, descontinuidade e lacunas. Com raras exceções, o tema não parece ter aglutinado o interesse de grupos ativistas ou de pesquisas por longos anos, o que permitiria um aprofundamento das bases teóricas, metodológicas e o monitoramento das ações. Consultando várias bases de dados, notamos que predominam autorias que publicaram um único título sendo raras aquelas que revisitaram ou se mantiveram fiéis ao tema. Os canais de divulgação, muitas vezes, são alternativos, específicos ou secundários, sendo relativamente pouco frequentes os de maior prestígio ou que atingiriam formadores de opinião nas áreas disciplinares relacionadas aos LD sob análise. Notamos reduzido debate teórico e metodológico, crítica interna acadêmica ou política, além da pequena escuta de professores(as) e alunos(as) usuários(as) dos LD, escuta que vem penetrando a produção acadêmica e ativista, inclusive em contexto escolar (Müller, 2006).

Por sua vez, é notável a quase que unanimidade da crítica e da palavra de ordem: os LD continuam sexistas e é necessário mudá-los. Afora alguns pesquisadores que consideram tais pesquisas simplificadoras ou pouco relevantes diante da complexidade das políticas de linguagem ou de LD, encontramos apenas uma autora, Diane Ravitch, que faz críticas tanto à esquerda quanto à direita norte-americanas por banirem dos LD temas que geram controvér- 
sia na sociedade norte-americana. Para Ravitch (apud Harber, 2008), os LD norte-americanos chegam à escola já pré-censurados graças às mobilizações de fundamentalistas e movimentos de esquerda (cita o feminista), "censura" que acaba por produzir conteúdos incoerentes e enfraquecer a reflexão crítica ${ }^{5}$.

\section{LIVROS DIDÁTICOS, FEMINISMO E POLÍTICAS EDUCACIONAIS NO BRASIL}

Como ocorreu em vários países, no Brasil, a década de 1970 marcou a mudança de paradigma na compreensão das desigualdades sociais entre homens e mulheres, destacando-se a educação na construção dessas desigualdades e, em decorrência, a emergência da palavra de ordem de combate à educação diferenciada para meninos e meninas. Assim, na primeira manifestação pública do feminismo brasileiro contemporâneo, a crítica aos "estereótipos sexuais na escola" já se fazia presente, com menção aos LD:

A escola em si mesma não é responsável pelos estereótipos culturais: todavia, funciona como mais uma agência de socialização a fortalecê-los [...] a ideologia da escola está longe de ser vanguardista em relação aos papéis sexuais. Os livros de textos utilizados pelos professores retratam em geral modelos de papéis sexuais tradicionais. (Mello, 1975, p. I42)

A partir de então, o tema estereótipos sexuais, ou de gênero, produzidos ou veiculados pelos LD, adentrou a literatura acadêmica, a agenda feminista e, posteriormente, sobretudo a partir da década de 1980, a dos governos federal, estaduais e municipais. O tema penetrou o Programa Nacional do Livro Didático - PNLD - que, em 2007, comprou 102,5 milhões de exemplares produzidos por editoras privadas e distribuídos gratuitamente nas escolas públicas e comunitárias.

Como em outros países, a delimitação dessa questão como problema social a ser enfrentado e resolvido e sua manutenção na agenda interage com

5. Conforme a resenha de John Harber, o livro foi produzido a partir da experiência de Ravitch, durante e no governo Clinton, para elaborar princípios de avaliação dos LD. 
processos políticos e sociais mais amplos. Quando se iniciou o feminismo contemporâneo brasileiro, o país vivia sob regime de ditadura militar, contra o qual se aliaram progressistas de esquerda, principalmente de formação marxista, das igrejas, dos partidos políticos e sindicatos e dos chamados novos movimentos sociais. A agenda do nascente movimento feminista brasileiro carregou as marcas dessa aliança, tendo como ícone de suas reivindicações a mulher trabalhadora adulta (Sarti, 1988). Assim, alguns temas da pauta feminista internacional foram postergados (como "nosso corpo nos pertence") e outros, como o combate à educação diferenciada, entraram parcimoniosamente na agenda política e na pauta acadêmica. Desde então, o campo de estudos sobre a mulher/relações de gênero, de certa forma, tem valorizado pouco a educação, da mesma forma que a educação tem pouco valorizado estudos sobre mulheres/gênero (Rosemberg, 200I).

Nesse contexto, a produção sobre sexismo nos LD, apesar de ter se mantido em cenário acadêmico desde 1975, é, também no Brasil, esporádica, de autorias individuais, sem se organizar em grupos que debatam divergências teóricas ou políticas ou efetuem o monitoramento de permanências e mudanças no conteúdo dos LD.

Uma das particularidades da produção acadêmica brasileira sobre o tema, parcialmente decorrente do enfoque teórico e político em sua constituição, bem como das alianças que sedimentaram suas origens, foi a atenção simultânea, em alguns estudos, da perspectiva das desigualdades de gênero, raça e geração (Pinto, 1981; Piza, 1995; Moura, 2007).

\section{Produção acadêmica e ativismo feminista}

Três estados da arte sobre mulher/gênero e LD foram produzidos entre 1989 e 2007 no Brasil: Negrão e Amado (1989); Rosemberg, Piza e Montenegro (1990), que discutiram o LD no contexto amplo de revisão da literatura sobre mulher e educação formal no país; Moura (2007) que analisou a produção a partir de 1986 até a atualidade.

Negrão e Amado (1989), que tratam do período 1973 a 1986, aqui denominado primeiro período, efetuaram o estudo por encomenda do então recém-criado Conselho Nacional dos Direitos da Mulher - CNDM. As autoras levantaram 44 referências bibliográficas, entre artigos, comunicações, teses e 
livros que mencionavam ou tiveram por objetivo analisar a "imagem da mulher" nos LD. Destacam: a maior parte das referências data da primeira metade dos anos 1980, mas a produção se inicia em 1972; uma cobertura relativa do território nacional; uma grande variedade dos suportes (número de páginas, tipo de publicação etc.), contrabalançada pela análise quase que exclusiva de LD contemporâneos e destinados à escola primária. Foram raras as pesquisas que se detiveram em livros para o pré-primário (Eluf, 1979), secundário (Chaim, 1981), superior (Ratto, 1989). Também foram poucas as pesquisas que analisaram LD em perspectiva histórica (Reis, 1989), ou rastrearam um longo período (Pinto, 198I).

Uma parte dos estudos inspirou-se na literatura norte-americana e europeia sobre sexismo em LD. Os procedimentos metodológicos apoiaram-se na análise de conteúdo, de forma nem sempre adequada. Algumas das pesquisas se calcaram nos trabalhos de Boggio et al. (1973) e de Bonazzi e Eco (1980), que se detêm apenas secundariamente nos estereótipos sexuais. Algumas pesquisas se ancoraram na "vulgata marxista" (Freitag, Motta, Wanderly, 1987). Percebe-se um maniqueísmo latente em parte da produção inicial, canhestra, ainda, no manejo de teorias e pouco afeita ao uso de técnicas ditas objetivas, que recebiam, em certos círculos acadêmicos, o epíteto de positivistas. Poucas pesquisas trataram da recepção.

Os resultados não apresentam novidades diante do que vinha sendo enunciado no exterior: personagens femininos subrrepresentados no texto e nas ilustrações (Pinto, 1981); merecendo menor destaque textual que os masculinos (Lins, 1983); pouco individualizados, sendo preferencialmente designados por função familiar (Pinto, 1981) e por apelidos, muitas vezes pejorativos quando negros (Jesus, 1986); frequentemente associados a contextos domésticos (Lajolo, 1982; Rego, 1976; Ribeiro, 1981); seus comportamentos e atributos são predominantemente de tipo passivo, frágil, submisso, servil, lábil (Eluf, 1979; Lajolo, 1982; Pinto, 1981; Lins, 1983); personagens femininas adultas mais frequentemente representadas como donas de casa, mães de família, sendo poucas as que exercem trabalho fora de casa (Rego, 1976; Eluf, 1979; Faria 1984; Nosella, 1979; Pinto, 1981; Ribeiro, 1981, Lajolo, 1982; Lins, 1983); predomínio do lazer feminino doméstico e passivo (Eluf, 1979; Ribeiro, 1981; Lins, 1983). O perfil masculino seria o oposto ao feminino, acrescido de qualidades e atividades intelectuais (Pinto, 1981). A caracterização 
de personagens pertencentes a outros segmentos étnico-raciais (Telles, 1987; Pinto, 1981; Jesus, 1986) evidencia exacerbação dos estereótipos: a personagem negra aparece especialmente como empregada doméstica (Pinto, 1981) e sem família (Jesus, 1986); a mulher índia como infantil, sensual, desocupada (Telles, 1987).

Dentre as pesquisas, merece destaque, pela perspectiva teórica que adotou, pelo cuidado na metodologia empregada e pela abrangência, a dissertação de Regina Pahim Pinto, O livro didático e a democratização da escola ( $198 \mid$ ). A pesquisadora analisou 48 livros de leitura indicados para uso da $4^{\mathrm{a}}$ série das escolas primárias do Estado de São Paulo, no período de 1941 a 1975. Observou que praticamente todos os indicadores, suscetíveis de captar uma posição de destaque na ilustração e no texto, privilegiam as personagens masculinas em detrimento das femininas.

As pesquisas brasileiras sobre estereótipos em LD do primeiro período foram realizadas objetivando a explicitação e denúncia de discriminações de sexo; ofereceram um modelo explicativo na argumentação sobre manutenção de comportamentos tradicionais e passivos entre as mulheres (quase behaviorista); algumas contribuíram para avançar o conhecimento sobre a escola e muitas delas serviram como ponto de apoio para a sensibilização do magistério quanto à educação diferenciada de meninos e meninas. Isso porque ocorreu, então, divulgação via debates, palestras, artigos na grande imprensa, programas de televisão, videoteipes e audiovisuais (Rosemberg, Pinto, Negrão, 1985) - o que pode ser atribuído ao dinamismo do período de abertura política e sua receptividade à crítica a padrões culturais tradicionais, bem como à assimilação imediata dos resultados das pesquisas, pois revelaram descrições caricatas, ou quase, veiculadas pelo material didático mais popular entre professores(as). O aspecto caricato decorria tanto do conteúdo dos LD, quanto do estilo da crítica acadêmica e ativista que, com raras exceções, buscava dicotomias, e não tendências, na representação das personagens: Enquanto Adão lia o jornal, Eva lavava a roupa (Rosemberg, 1986). Usava-se uma linguagem que pode favorecer uma forma de identificação distanciada do público feminino com os estereótipos descritos - o que se descreve nos LD é próximo e distante da própria experiência de mulher -, o que gera adesão suficiente para manifestar indignação.

Lamentavelmente, a produção crítica sobre LD no geral (veja-se Freitag, Motta, Wanderly, 1987) praticamente ignorou o que se escreveu e 
refletiu sobre imagens de papéis sexuais. Como afirmam Negrão e Amado (1989), os canais de divulgação acadêmica foram fechados e determinados por modismos e soluções de facilidade. Algumas das dissertações/teses que se transformaram em livro e que se tornaram mais acessíveis, foram talvez as mais denuncistas, e, a nosso ver, pouco contribuíram para consolidar esse campo do conhecimento. Também, lamentavelmente, a produção sobre sexismo nos LD ignorou o grande debate sobre políticas do LD no contexto das reformas de ensino, bem como as inovações pedagógicas e metodológicas nas disciplinas cujos livros estavam analisando. Por exemplo, que impacto poderia ter na imagem do masculino e feminino a inovação no currículo do ensino da Língua Portuguesa que passou a preconizar pluralidade de gêneros textuais e ênfase na oralidade?

Analisando a produção de 1980 a 2000, Moura (2007) observa permanências e alterações no tratamento dado ao tema. Destaca que o tema permanece na agenda do movimento feminista. Por exemplo, Farah ( 1998) identifica "o combate à discriminação da mulher nos LD" como um dos tópicos que localizou nos programas e projetos de organizações de mulheres e feministas da década de 1990. Além disso, a Plataforma Política Feminista de 2004 e o Plano Nacional de Políticas para as Mulheres (Brasil, 2004) mantêm o quesito de avaliação, seleção e distribuição de LD que garantam "o cumprimento adequado dos critérios referentes à não discriminação de gênero, raça, etnia e orientação sexual", bem como seu monitoramento, o incentivo à produção de LD não discriminatórios e a formação de professores (p.57) ${ }^{6}$.

No plano acadêmico, a autora observa a ampliação de recortes disciplinares e níveis escolares dos LD analisados; a introdução do termo gênero em substituição a sexo; a difusão privilegiada dos trabalhos em congressos acadêmicos feministas. Moura (2007) identifica a elaboração de novas 20 teses/dissertações entre 1986 e 2006, várias comunicações apresentadas no congresso bienal Fazendo Gênero, mas poucos trabalhos apresentados

6. Em 1990, o Conselho Nacional dos Direitos da Mulher - CNDM - instituiu o prêmio Nísia Floresta para incentivar a produção de LD não sexista, mas que conferiu apenas uma menção honrosa em decorrência da qualidade insuficiente das propostas. $\bigcirc 2^{\circ}$ Plano Nacional de Políticas para as Mulheres (2008) introduziu, entre as I I novas áreas de atuação, o "Enfrentamento ao racismo, sexismo e lesbofobia" à qual se uniu o tema já incluído na versão anterior de "Educação inclusiva e não sexista" (CFEMEA, 2008, p.3). 
nas reuniões anuais da Associação Nacional de Pesquisa e Pós-graduação em Educação - Anped.

Assim, compulsando os anais das reuniões anuais da Anped (1998 a 2007) ${ }^{7}$, observamos que foram apresentadas 2.77 I comunicações e 773 pôsteres, dentre eles 38 comunicações e 13 pôsteres versaram sobre LD, mas apenas um em cada categoria tratou do tema sexismo nos LD, mesmo usando variados descritores na busca ${ }^{8}$. Além disso, notamos a praticamente ausência de artigos publicados em revistas acadêmicas. Isto é, a difusão de estudos e pesquisas permanece em circuitos relativamente fechados. Que produtor de LD frequenta congresso feminista ou lê uma tese/dissertação?

No conjunto das pesquisas permanecem lacunas: pouco se trata do uso que fazem deste material professores(as) e alunos(as), das dificuldades de criação de material alternativo e o que isso significa na sociedade brasileira; das formas de utilização contra-corrente desses materiais, das implicações do fato de o Estado ser hoje, no Brasil, o maior comprador de LD e do perfil do mercado de trabalho do LD do ponto de vista das relações de gênero, entre outros aspectos.

Uma síntese dos resultados relatados nessas pesquisas sugere persistência de padrões tradicionais convivendo com atenuação das tendências. Por exemplo, Amaral (2004), ao estudar as imagens da família em LD, percebe a convivência de valores "modernizantes e antigos"; Tonini (2002) apreende a "reafirmação da polaridade" masculino-feminino, uma separação espacial que "captura homens e mulheres em territórios opostos"; Casagrande (2005) relata a persistência de "papéis dicotomizados", a "não incorporação" pelos LD de "mudanças nas relações de gênero ocorridas nesta virada do milênio", ao analisar livros de Matemática.

Aparentemente, a ruptura com padrões tradicionais seria mais intensa na literatura infanto-juvenil. Por exemplo, estudos apontam que algumas autoras contemporâneas criam "figuras femininas ativas e questionadoras" (Oliveira, 2005) ou problematizam a dominação masculina. Porém, em seu conjunto Amaral (2004) e Nogueira (200 I) assinalam, também, a persistência, embora

7. Consulta em CD ROM.

8. Os descritores usados foram: sexo, sexismo, papel sexual, feminismo, mulher(es), homem(s), masculinidade, relações de gênero, gênero, discriminação, desigualdades, estereótipos. 
atenuada, de conteúdos tradicionais como a subrrepresentação feminina e a tendência à associação do masculino à atividade e ao espaço externo e do feminino à passividade e contexto familiar.

Algumas pesquisas avançam na busca de compreensão das tensões entre relações de gênero, raça e idade na literatura infanto-juvenil: Rosemberg e Piza (1995) assinalam que a entrada da crítica feminista estimulou, por vezes, a produção de textos "missionários, dogmáticos, que nem sempre divergem, em sua armadura, das produções mais tradicionais" (p.6 I I). Porém, identificam ruptura na obra da consagrada autora de livros infanto-juvenis, Lygia Bojunga Nunes (prêmio Hans Cristian Andersen), que consegue integrar uma perspectiva emancipadora tanto na ótica das relações de gênero quanto das de idade. Piza ( 1995 ) encontra um impacto paradoxal da "nova literatura infanto-juvenil" brasileira da lavra de escritoras brancas que, ao romperem com tabus tradicionais introduzindo o tema da sexualidade, o fazem via a criação de personagens femininas negras sexualizadas ou sensualizadas, uma "importação" na literatura infanto-juvenil de estereótipos da "mulata", até então exclusivos da literatura brasileira para adultos.

Mais recentemente, no contexto da implantação da Lei n. 10.639/03, que torna obrigatório, nos estabelecimentos de ensino fundamental e médio, oficiais e particulares, o ensino sobre História e Cultura Afro-Brasileira, Souza (2005) assinala a publicação de alguns textos de literatura infanto-juvenil que "passaram a apresentar e enfatizar positivamente aspectos da cultura negra como a capoeira e a mitologia dos orixás. São encontradas situações de reflexão sobre a vida e a imagem da personagem negra feminina de maneira positiva e criativa" (p. 199).

Os LD também foram objeto de pesquisas que se voltam para longos períodos e, em perspectiva diacrônica, procuram apreender o que permaneceu e o que mudou. Pires (2002) analisou 205 ilustrações contidas em 17 LD de Língua Portuguesa publicados entre as décadas de 1980 e 1990 , constatando que "há poucas mudanças relativas a novas posições de sujeitos para as mulheres. O que aparece, em algumas obras, são elas mostrando-se com roupas modernas, trabalhando fora de casa, desempenhando outras atividades diferentes das caseiras" (Pires, 2002, p. I 16). Casagrande e Carvalho (2006) relatam resultados da análise de 18 LD de Matemática, quatro deles datados do início de 1990 e os demais de 2000, destinados às $5^{\mathrm{a}}$ e $6^{\mathrm{a}}$ séries 
do ensino fundamental. Concluem que os LD "analisados não incorporam as transformações nas relações sociais ocorridas nas últimas décadas, visto que houve pouca diferença na forma de representar os gêneros nos dois períodos analisados" (p. | 4).

Merecem destaque as pesquisas de Silva (2008) sobre relações raciais e Moura (2007) sobre relações de gênero que atualizaram a pesquisa de Pinto ( 1981 ), analisando LD de Língua Portuguesa para o $4^{\circ}$ ano do ensino fundamental, o que permitiu apreender permanências e mudanças nas configurações do racismo e do sexismo no longo período de 194I a 2003. A pesquisa analisou 1.372 personagens identificados no texto, 626 nas ilustrações e 120 nas capas, agrupados por períodos conforme as iniciativas do governo federal quanto à política do LD. As autoras constataram um aumento de mulheres autoras de LD, maior diversidade de gêneros textuais no período mais recente (mas ainda com predomínio da literatura infantil), manutenção atenuada dos padrões identificados por Pinto ( $198 \mid$ ) de racismo e sexismo e convivência, lado a lado em alguns livros contemporâneos, de temas da agenda feminista com imagens arcaicamente sexistas. Além disso, notaram menor intensidade de desigualdades de gênero que as de raça. Por exemplo, entre outros aspectos, encontraram no texto I personagem mulher para 2,3 personagens homens e I personagem não-branca para 9,7 personagens brancas. A destacar, ainda, a observação de que as desigualdades de idade, raça e gênero eram menos acentuadas nas capas que nas ilustrações, diferença interpretada como um jogo de sedução comercial (Quadro I). Isto é, a capa sendo o primeiro contato com o livro, funciona, até certo ponto, como embalagem. Moura (2007, p. I 53) sintetiza suas observações: "Tais tendências não se alteram com o passar dos anos [...] A inclusão da perspectiva de gênero na avaliação dos LD não foi suficiente para alterar padrões anteriores na configuração dos masculinos e femininos".

A partir de 1996 os LD comprados pelo MEC passaram pela avaliação do PNLD que estabelece que "os livros não podem expressar preconceitos de origem, raça, sexo, cor, idade e quaisquer outras formas de discriminação" (Brasil, 1997). Como entender tal resistência à mudança se o combate ao "preconceito de gênero" constitui um critério eliminatório para a compra e distribuição de LD pelo MEC? Essa pergunta nos obriga a vasculhar um pouco mais a política nacional do LD. 
QUADRO I

INDICADORES SELECIONADOS REFERENTES A UMA AMOSTRA DE 33 LIVROS DIDÁTICOS BRASILEIROS DE LÍNGUA PORTUGUESA PARA 4a SÉRIE DO ENSINO FUNDAMENTAL ( 1975 - 2003)

\begin{tabular}{|c|c|c|c|c|c|c|c|c|}
\hline \multirow{2}{*}{\multicolumn{2}{|c|}{$\begin{array}{l}\text { I) Distribuição de persona } \\
\text { Período }\end{array}$}} & \multicolumn{7}{|r|}{ odo } \\
\hline & & \multicolumn{2}{|c|}{ de 1975 a 1995} & \multicolumn{3}{|c|}{ de 1996 a 2003} & \multicolumn{2}{|c|}{ Total } \\
\hline \multicolumn{9}{|l|}{ Grupos etários } \\
\hline \multicolumn{2}{|l|}{ Adulto + velho } & 429 & $51,2 \%$ & 308 & \multicolumn{2}{|c|}{$57,7 \%$} & 737 & $53,7 \%$ \\
\hline \multicolumn{2}{|c|}{ Criança + bebê+jovem } & 337 & $40,2 \%$ & 68 & \multicolumn{2}{|c|}{$31,5 \%$} & 505 & $36,8 \%$ \\
\hline \multicolumn{2}{|l|}{ Indeterminado } & 72 & $8,6 \%$ & 58 & \multicolumn{2}{|c|}{$10,9 \%$} & 130 & $9,5 \%$ \\
\hline \multicolumn{2}{|l|}{ Total } & 838 & $100,0 \%$ & 534 & \multicolumn{2}{|c|}{$100,0 \%$} & 1373 & $100,0 \%$ \\
\hline \multicolumn{9}{|l|}{ Cor/etnia } \\
\hline \multicolumn{2}{|l|}{ Branca } & 408 & $48,7 \%$ & 290 & \multicolumn{2}{|c|}{$54,3 \%$} & 698 & $50,9 \%$ \\
\hline \multicolumn{2}{|c|}{ Preta + parda + indígena } & 51 & $6,1 \%$ & 21 & \multicolumn{2}{|c|}{$3,9 \%$} & 72 & $5,2 \%$ \\
\hline \multicolumn{2}{|l|}{ Indetermina } & 379 & $45,2 \%$ & 223 & \multicolumn{2}{|c|}{$41,8 \%$} & 602 & $43,9 \%$ \\
\hline \multicolumn{2}{|l|}{ Total } & 838 & $100,0 \%$ & 534 & \multicolumn{2}{|c|}{$100,0 \%$} & 1372 & $100,0 \%$ \\
\hline \multicolumn{9}{|l|}{ Sexo } \\
\hline \multicolumn{2}{|l|}{ Masculino } & 490 & $58,5 \%$ & 322 & \multicolumn{2}{|c|}{$60,3 \%$} & 812 & $59,2 \%$ \\
\hline \multicolumn{2}{|l|}{ Feminino } & 241 & $28,8 \%$ & 112 & \multicolumn{2}{|c|}{$21,0 \%$} & 353 & $25,7 \%$ \\
\hline \multicolumn{2}{|l|}{ Misto/indeterminado } & 107 & $12,8 \%$ & 100 & \multicolumn{2}{|c|}{$18,7 \%$} & 207 & $15,1 \%$ \\
\hline \multicolumn{2}{|l|}{ Total } & 838 & $100,0 \%$ & 534 & \multicolumn{2}{|c|}{$100,0 \%$} & 1372 & $100,0 \%$ \\
\hline \multicolumn{9}{|c|}{$\begin{array}{l}\text { 2) Distribuição de personagens quanto à referência a família e ocupação/trabalho, segundo o } \\
\text { período e o sexo }\end{array}$} \\
\hline Porínde covo & & de 197 & 75 a 1995 & & & de & 96 a 2003 & \\
\hline Periodo e sexo & & culino & & inino & & culino & & $\operatorname{minino}$ \\
\hline $\begin{array}{l}\text { Referência à família } \\
\text { do personagem }\end{array}$ & 118 & $24,1 \%$ & 102 & $42,3 \%$ & 72 & 22,4 & 51 & $45,5 \%$ \\
\hline $\begin{array}{l}\text { Referência ao } \\
\text { trabalho/ocupação } \\
\text { do personagem }\end{array}$ & 95 & $19,4 \%$ & 36 & |4,9\% & 115 & 35,7 & 25 & $22,3 \%$ \\
\hline Total & 490 & $100,0 \%$ & 241 & $100,0 \%$ & 322 & 100,0 & 112 & $100,0 \%$ \\
\hline
\end{tabular}

Fonte: Reorganização de dados inicialmente coletados e processados por Silva (2005) e Moura (2007).

Obs.: Processamento efetuado por Miriam Bizzocchi. 


\section{POLÍTICAS CONTEMPORÂNEAS BRASILEIRAS DO LD E A PERSPECTIVA DE GÊNERO}

A persistência de padrões sexistas no LD convive com declarações e ações do Estado brasileiro visando ao tratamento igualitário de mulheres e homens na educação. Assim, o Brasil foi signatário de todos os acordos internacionais na matéria, enfatizando, quando a ocasião se apresentava, que nosso sistema educacional garante igualdade de acesso a homens e mulheres. Notáveis também têm sido as ações que o governo federal vem assumindo e que propiciaram introduzir o tema das discriminações de gênero na educação e nos LD. Localizamos quatro principais ações, resumidas a seguir? ${ }^{9}$.

- Ministério da Justiça, que abrigava o CNDM, e MEC assinaram, em 1996, protocolo de colaboração para o combate à discriminação contra as mulheres na educação, que seria incluído como um dos critérios a serem considerados na avaliação dos LD comprados e distribuídos pelo MEC, no contexto da sistemática que estava sendo instituída sobre a política do LD.

- Os Parâmetros Curriculares Nacionais (PCN, 1997) incluíram como objetivo questionar padrões de desigualdade de gênero e incentivar, na escola, a "diversidade de comportamento de homens e mulheres", o "respeito pelo outro sexo" e "pelas variadas expressões do feminino e masculino" (Brasil, apud Vianna, Unbehaum, 2004, p. I6).

- A avaliação dos LD incluiu, a partir de 1996, um quesito que atenta a "preconceitos de origem, raça, sexo, cor, idade e quaisquer outras formas de discriminação" (Brasil, 1997) ${ }^{10}$.

- O Plano Nacional de Educação (200 I) incluiu critério de avaliação do LD (além da correção conceitual e de aspectos metodológicos) relativo à "adequada abordagem das questões de gênero e etnia e a

9. No que diz respeito ao combate ao racismo, a Lei federal n. 10.639/2003, que introduziu a obrigatoriedade de História da África e da Cultura Afro-Brasileira no currículo das escolas brasileiras, foi complementada pela Lei n. I I.645/2008, que aí também incluiu a obrigatoriedade da temática indígena.

10. A partir de 2000, a formulação foi alterada, substituindo-se o termo raça por cor e o termo sexo por gênero. 
eliminação de textos discriminatórios ou que reproduzam estereótipos acerca do papel da mulher, do negro e do índio" (Vianna, Unbehaum, 2004, p. 13).

Portanto, desde 1996, o "preconceito" de sexo/gênero constitui um dos critérios para eliminar LD do sistema oficial brasileiro de compra e distribuição. Silva (2008) procedeu à análise dos bastidores desses avanços na sistemática de análise dos LD, destacando como se deu a participação dos movimentos sociais ". Com base em depoimentos de técnicos que atuam na administração federal, assinala que os seminários realizados nos anos 1980 e 1990 sobre o tema estereótipos de gênero/raça fortaleceram o poder de negociação do MEC com as editoras resistentes, até então, restrito a processos oficiais de avaliação dos LD. Com sua posição fortalecida, o MEC iniciou nova estratégia de pressão das editoras, desta feita fazendo vazar para a imprensa os resultados da avaliação de 1993, que encontrara erros conceituais grosseiros nos LD comprados pelo governo federal e distribuídos às escolas. Tal estratégia fez com que as editoras acatassem a definição de critérios para a avaliação dos LD e a aliança do MEC com os movimentos negro e feminista; a partir de então, deixou de ser importante. Assim, apesar de a veiculação de racismo e sexismo permanecer como critério excludente nos editais de licitação dos LD, as comissões de avaliação são compostas exclusivamente por professores universitários especialistas nas áreas disciplinares dos LD que avaliam. Portanto, dada a peculiaridade da produção acadêmica sobre sexismo/racismo nos LD - que permanece em gueto, no formato de teses/dissertações, pouco produzida e difundida nas áreas disciplinares, como vimos -, pode-se supor que as comissões de avaliação do LD constituídas pelo MEC não têm uma formação consistente sobre racismo e sexismo discursivo, além daquela compartilhada pelo senso comum. Além disso, note-se que os critérios adotam o termo preconceito, e não estereótipo (é vedado "veicular preconceitos de origem, cor, condição econômica-social, etnia, gênero e qualquer outra forma de discriminação"), que pode ser interpretado como sinônimo apenas de conteúdos que explicitam abertamente,

II. A partir de 1996, os critérios de avaliação dos LD a serem comprados e distribuídos pelo MEC atentam para três aspectos: conceitual, metodológico e "político", este último incluindo, entre outros aspectos, a veiculação de preconceitos. 
e não veladamente, concepção desfavorável a segmentos étnico-raciais e à mulher. Por exemplo, representar personagens femininas principalmente no exercício da maternidade constitui expressão de preconceito?

Tais questões foram colocadas por Beisiegel (200I) no estudo que realizou sobre os pareceres emitidos pela Comissão de Avaliação de LD de Língua Portuguesa em 1998. Analisando pareceres emitidos pela Comissão sobre livros que haviam sido recusados ("excluídos") ou que obtiveram uma baixa qualificação ("não recomendados"), observa que, "não obstante o rigor da análise realizada pelas equipes de especialistas", "estereótipos, discriminações ou preconceitos" sustentaram "apenas excepcionalmente" as classificações atribuídas. Para o autor, "ressalvadas as poucas exceções [...], os pareceres do PNLD, nos itens sobre etnia e gênero, retornam aos pontos de partida da análise de livros didáticos de 50 e 60, limitando-se à captação de manifestações explícitas dos fenômenos" (p.29).

E foi exatamente isto que observamos na análise de Val e Castanheira (2005), especialistas em Língua Portuguesa, uma delas participante da Comissão de Avaliação, que, em síntese, assinalam sobre a qualidade dos LD avaliados pelo MEC em 2004: "nenhuma das obras avaliadas foi excluída por apresentar preconceitos de qualquer tipo, inclusive linguístico, fato que, por si só, é indicativo de que autores e editores estão atentos a esse critério de eliminação" (p. I 5 I). Ou seja, a sensibilidade do filtro interposto pela Comissão de Avaliação foi considerada acima do bem e do mal. Deve-se ter em mente que, de modo geral, as comissões de avaliação são rigorosas para os outros critérios, tendo reprovado vários títulos, ou atribuído a eles baixa classificação (Val, Castanheira, 2005).

Analisando as sínteses elaboradas pelo MEC (Brasil, 2006) e publicadas no Guia de livros didáticos de língua portuguesa 2007, distribuídos a todas as escolas para que os(as) professores(as) conheçam as coleções e selecionem os livros que serão usados por seus alunos durante três anos, não encontramos qualquer informação sobre o tratamento dado pelos livros ali apresentados a preconceitos, estereótipos ou discriminações. Isto é, a minuciosa descrição de cada coleção (cinco páginas impressas para cada uma) se centra, exclusivamente, em critérios teóricos, conceituais e metodológicos relacionados ao ensino-aprendizado da Língua Portuguesa, critérios que, por sua vez, não são considerados pelos estudos que tratam do sexismo em LD. 
Tais procedimentos adotados na avaliação dos LD e a constatação de permanência de estereótipos têm impulsionado a reivindicação de que representantes de movimentos sociais (negro, indígena e feminista) e de professores usuários dos livros participem das comissões de avaliação (Silva Jr., 2002; Brasil, 2004).

Esta proposta simplifica, porém, a complexidade da missão, posto que as desigualdades sociais não atingem de mesmo modo os diferentes segmentos sociais, os movimentos sociais não são monolíticos internamente, tampouco compartilham de agendas políticas idênticas ou dispõem de mesmo repertório para apreender estereótipos e discriminações, ou ainda para produzir livros livres de discriminações de gênero, raça e idade que satisfaçam a todos. No caso brasileiro, a questão se torna mais complexa quando lembramos que gerações de meninas, brancas e não brancas, que estão usando esses LD vêm obtendo, em média, melhores resultados escolares, especialmente em Língua Portuguesa, que os meninos, brancos e não brancos. Que proposta de avaliação de impacto dos LD, como quer Blumberg (2007), podemos elaborar diante desses paradoxos? Afinal, que objetivos procuramos atingir a partir da crítica ao sexismo nos LD?

\section{REFERÊNCIAS BIBLIOGRÁFICAS}

AMARAL, I. C. Representações do feminino e masculino nas estórias infantis. Curitiba, 2004. Dissert.(mestr.) Universidade Federal do Paraná.

BAUDELOT, C.; ESTABLET, R. Quoi de neuf chez les filles? Entre stéréotypes et libertés. Paris: Nathan, 2007.

BEAUVOIR, S. O Segundo sexo: a experiência vivida. São Paulo: Difusão Européia do Livro, 1960.

BECCHI, E.; JULIA, D. (orgs.). Histoire de l'enfance en occident: du XVIII siècle à nos jours. Paris: Seuil, 1998.

BEISIEGEL, C. Cultura e democracia. Rio de Janeiro: Fundo Nacional de Cultura, 2001.

BELOTTI, E. G. Dalla parte delle bambine. Milano: Giangiacomo Feltrinelli, 1973.

BLUMBERG, R. L. Gender bias in textbooks: a hidden obstacle on the road to gender equality in education. Unesco, 2007. 
BOGGIO, A. et al. La Ideologia en los textos escolares peruanos. Comunicación y Cultura, n. I, p. 102-1 |4, 1973.

BONAZZI, M.; ECO, U. Mentiras que parecem verdades. São Paulo: Summus, 1980.

BRASIL. Instituto Nacional de Estudos e Pesquisas Educacionais. Plano Nacional de Educação: PNE. Brasília, 200I.

BRASIL. Leis e decretos. Lei federal n. 10.639, de 9 de janeiro de 2003: estabelece as diretrizes e bases da educação nacional, para incluir no currículo oficial da rede de ensino a obrigatoriedade da temática "História e Cultura Afro-Brasileira". Brasília, 2003.

BRASIL. Ministério da Educação. Guia do livro didático ( ${ }^{a}$ a $4^{a}$ série): PNLD/FNDE, 1998. Brasília: Imprensa Nacional, 1997.

Guia do livro didático 2007: língua portuguesa: séries/anos iniciais do ensino fundamental. Brasília, 2006.

Parâmetros curriculares nacionais: ensino fundamental. Brasília, I997a.

BRASIL. Secretaria Especial de Políticas para as Mulheres. Plano nacional de políticas para as mulheres. Brasília, 2004.

BRUGEILLES, C.; CROMER, S.; LOCOH, Th. Réseau international des recherches sur les représentations sexuées dans les manuels scolaires (Introdución, 2). In: CEPED. Analyser les représentations sexuées dans les manuels scolaires: application d'une méthode commune dans six pays: Cameroun, Madagascar, Mexique, Sénégal, Togo et Tunisie. Paris. Disponível em: www.ceped.org/cdrom/manuels_scolaires/ sp/sigles.html. Acesso em: ago. 2009.

CABREJO, F. M. De qué políticas educativas hablamos en el Perú? La incorporación del género en la educación. In: STROMQUIST, N. P. (org.) La Construcción del género en las políticas públicas: perspectivas comparadas desde América Latina. Lima: IEP, 2006. p.63-I I 3.

CALERO, M. et al. Los Textos escolares en primaria. In: BINI, G.et al. (orgs.) Los Libros de texto en América Latina. México: Nueva Imagen, 1977. p. 127- 153.

CASAGRANDE, L. S. Quem mora no livro didático? Representações de gênero nos livros de matemática na virada do milênio. Curitiba, 2005. Dissert. (mestr.) Centro Federal de Educação Tecnológica do Paraná.

CASAGRANDE, L. S.; CARVALHO, M. G. Educando novas gerações: representações de gênero nos livros didáticos de matemática. Caxambu: Anped, 2006. Disponível em: www. anped.org.br/reunioes/29na/trabalhos/.../GT23-2066-Int.pdf. Acesso em: jul. 2008 
CENTRO FEMINISTA DE ESTUDOS EASSESSORIA - CFEMEA. Jornal Fêmea, n. 1 56, 2008. Disponível em: http://www.cfemea.org.br/jornalfemea/detalhes.asp?IDJornalFemea $=\mid 476$. Acesso em: 10 out. 2008.

CHAIM, C. Em casa, quem manda é o papai. Mulherio, São Paulo, v. I, n. 4, nov./dez. 1981 . CHILD, I. L.; POTTER, E. H.; LEVINE, E. M. Children's textbooks and personality development: an exploration in the social psychology of education. Psychological Monographs, n. 60, p. I-54, 1946.

CHOPPIN, A. História dos livros e das edições didáticas: sobre o estado da arte. Educação e Pesquisa, v. 30, n. 3, p.549-566, set./dez. 2004.

CLARK, R.; KULKIN, H.; CLANCY, L., The Liberal feminist bias in feminist social science research on children's books. In: CLARK, B. L.; HIGGONET, M. R. (orgs.) Girls, boys, books, toys: gender, children's literature, and culture. Baltimore: Johns Hopkins, 1999. p.7I-82.

DECROEUX-MASSON, A. Papa lit, mama coud: les manuels scolaires en bleu et rose. Paris: Denoël, Gonthier, 1979.

ELUF, M. L. K. Papéis sexuais analisados na disciplina Moral e Cívica. Ciência e Cultura, v. 32, n. 7 supl., p.726, jul. 1979. (Resumos SBPC)

FARAH, M. F. S. Incorporação da questão de gênero pelas políticas públicas na esfera local do governo. São Paulo, 1998. Dissert. (mestr.) Fundação Getúlio Vargas.

FARIA, A. L. G. Ideologia no livro didático. São Paulo: Cortez; Campinas: Autores Associados, 1984.

FAUR, E. (coord.) Sexismo y educación. Bogotá: Unicef, Dirección Nacional para la Equidad de la Mujer, s/d.

FREITAG, B.; MOTTA, V. R. C.; WANDERLY, F. Livro didático em questão. São Paulo: Cortez, 1987.

GIMENO, A. (dir.) Transmisión de los modelos femenino y masculino en los libros de texto de la enseñanza obligatoria. España: Instituto de la Mujer, 1999-2000. (Pesquisa)

GORNICK, V.; MORAN, B. K. Woman in sexist society: studies in power and powerlessness. New York: Signet Classics, Signette, Mentor and Plume Books, The New American Library, 197I.

HARBER, John. Call the cops. (Review of RAVITCH, Diane: The Language police: how pressure groups restrict what students learn. Disponível em: http://www.haberarts.com/ravitch. htm. Acesso em: 9 out. 2008. 
HILGARTNER, S.; BOSK, C. The Rise and fall of social problems: a public arena model. American Journal of Sociology, n.94, p.53-78, 1988.

HOLLANDA, G. A. A Pesquisa dos estereótipos e valores nos compêndios de história destinados ao curso secundário brasileiro. Boletim do Centro Brasileiro de Pesquisas Educacionais, v. 2, n. 4, 1957.

JESUS, I. F. A Educação eurocêntrica e seus reflexos na população negra estudante. São Paulo, nov. 1986. mimeo. (Palestra proferida no Hospital dos Servidores Públicos)

KINGSTON, A.; LOVELACE, T. Sexism and reading: a critical review of the literature. Reading Research Quarterly, 13, p. 133-161, 1977/1978.

LAJOLO, M. Usos e abusos da literatura na escola. Rio de Janeiro, Porto Alegre: Globo, 1982.

LINS, V. L. O. Os Estereótipos sexuais no livro didático. In: TOLEDO, R. et al. (orgs.) A Dominação da mulher: os papéis sexuais na educação. Petrópolis: Vozes, 1983. p.21-25.

LORRAINE, E.; KIMBERLY, D. No sissy boys here: a content analysis of the representation of masculinity in elementary school reading textbooks. Sex Roles, n.42, p.255-270, 2000.

LOZANO, S. R. Discurso. In: BRASLAVSKY, C. (org.). Mujer y educación desigualdades educativas en la América Latina y el Caribe. Santiago: Unesco, 1984. p. I26-131.

MELLO, G. N. Os Estereótipos sexuais na escola. Cadernos de Pesquisa, n. I 5, p. | 4 | - | 44, dez. 1975.

MICHEL, A. Não aos estereótipos: vencer o sexismo nos livros para crianças e nos manuais escolares. São Paulo: Conselho Estadual da Condição Feminina, Unesco, 1989.

MOLLO, S. L'École dans la société: psychosociologie des modèles éducatifs. Paris: Dunod, 1969.

MOURA, N. C. Relações de gênero em livros didáticos de língua portuguesa: permanências e mudanças. São Paulo, 2007. Tese (dout.) Pontifícia Universidade Católica de São Paulo.

MÜLLER, F. Infância nas vozes das crianças: culturas infantis, trabalho e resistência. Educação \& Sociedade, v.27, n.95, p.553-573, ago. 2006.

NEGRÃO, E. V.; AMADO, T. A Imagem da mulher no livro didático: estado da arte. São Paulo: FCC/DPE, 1989. (Textos FCC, 2)

NIELSEN, H.; BRONWYN, D. Discourse and the construction of gendered identities in education: working paper. In: BLUMBERG, R. L. Gender bias in textbooks: a hidden obstacle on the road to gender equality in education. Paris: Unesco, 2007. p.31. 
NOGUEIRA, D. M. S. Um olhar sobre discriminações sexuais na literatura infanto-juvenil brasileira contemporânea. São Paulo, 200 I. Dissert. (mestr.) Pontifícia Universidade Católica de São Paulo.

NOSELLA, M. L. C. D. As Belas mentiras: ideologia subjacente aos textos didáticos. São Paulo: Cortez, Moraes, 1979.

OLIVEIRA, A. M. A Circulação do livro escolar no Brasil oitocentista. Caxambu: Anped, 2005. PINGEL, F. Guide pour l'analyse et la révision des manuels scolaires. Paris: Unesco, 1999.

PINTO, R. P. O Livro didático e a democratização da escola. São Paulo, 198। . Dissert. (mestr.) Universidade de São Paulo.

PIRES, S. M. F. Representações de gênero em ilustrações de livros didáticos. Porto Alegre, 2002. Dissert. (mestr.) Universidade do Rio Grande do Sul.

PIZA, E. S. P. O Caminho das águas: estereótipo de personagens femininas negras na obra para jovens de escritoras brancas. São Paulo, 1995. Tese (dout.) Pontifícia Universidade Católica de São Paulo.

POVEY, H. Dimensões de gênero e desigualdades na escola: o impacto das identidades. In: SILVEIRA, M. L.; GODINHO, T. (orgs.) Educar para a igualdade: gênero e educação escolar. São Paulo: Coordenadoria Especial da Mulher, Secretaria Municipal de Educação, 2004. p. 157- 178.

PRADO, H. E. C. G. Análisis sociológico de los libros de lectura de nivel primario: estudio de los estereotipos sexuales. Cordoba: Universidad Nacional de Cordoba; OEA, 1980. (Serie Investigación, 3)

RATTO, M. L. R. Enfermeira: um ser entre parênteses. São Paulo, 1989. Dissert. (mestr.) Pontifícia Universidade Católica de São Paulo.

REGO, M. F. Leituras de comunicação e expressão: análise de conteúdo. São Paulo, 1976. Dissertação (mestr.) Fundação Getúlio Vargas.

REIS, M. C. D. Crescer, multiplicar, civilizar: destino da mulher nas orientações educacionais dos anos 1920/30 em São Paulo. Revista ANPUH, n. 19, p.83-1 I4, jul. 1989.

RIBEIRO, Z. D. Falas e silêncios no discurso pedagógico dos textos didáticos: análise dos estereótipos comportamentais masculinos e femininos veiculados pelos livros de Comunicação e Expressão - $1^{\circ}$ grau. Fortaleza, 1981. Dissert. (mestr.) Universidade Federal do Ceará.

RIGNAULT, S.; RICHERT, P. La Représentation des hommes et des femmes dans les livres scolaires. Paris: Centre de documentation française, 1997. 
ROSEMBERG, F. Caminhos cruzados: educação e gênero na produção acadêmica. Educação e Pesquisa, São Paulo, v.27, n. I, p.43-51, jan./jun. 2001.

Enquanto Eva lavava, Adão lia o jornal. Leia, v.7, n.89, p.44, 1986.

A Escola e as diferenças sexuais. Cadernos de Pesquisa, São Paulo, n. I5, p.78-85, dez. 1975.

La Famille et les relations familiales dans les livres pour enfants. Paris, 1969. Tese (dout.). Université de Paris. Literatura infantil e ideologia. São Paulo: Global, 1985.

ROSEMBERG, F.; PINTO, R. P.; NEGRÃO, E. V. A Educação da mulher no Brasil. São Paulo: Global, 1985.

ROSEMBERG, F; PIZA, E. P. As Meninas na literatura infanto-juvenil brasileira. Revista Psicologia: Teoria e Pesquisa, Brasília, v. II , n.3, p.217-221, set./dez. 1995.

ROSEMBERG, F; PIZA, E. P.; MONTENEGRO, T. Mulher e educação formal no Brasil: estado da arte e bibliografia. Brasília: Reduc, Inep, 1990.

SARTI, C. A. Feminismo no Brasil: uma trajetória particular. Cadernos de Pesquisa, São Paulo, n.64, p.38-47, fev. 1988.

SILVA Jr., H. Anti-racismo: coletânea de leis brasileiras; federais, estaduais, municipais. São Paulo: Oliveira Mendes, 2002.

SILVA, P. V. B. Racismo em livros didáticos: estudo sobre negros e brancos em livros de língua portuguesa. Belo Horizonte: Autêntica. 2008. (Col. Cultura negra e identidades)

Relações raciais em livros didáticos de língua portuguesa. São Paulo, 2005. Tese (dout.) Pontifícia Universidade Católica de São Paulo.

SOUZA, A. L. A Representação da personagem negra feminina na literatura infanto-juvenil brasileira In: SECAD/MEC (org.) Educação anti-racista: caminhos abertos pela Lei Federal n. 10.639/03. Brasília: MEC/Secad, 2005. p. 199.

TELLES, N. A Índia e o olho do branco. Mulherio, São Paulo, v.7, n.27, p. $17,1987$.

TEMPLE, J. R. People who are different from you: heterosexism in Quebec high school textbooks. Canadian Journal of Education, v.28, n.3, p.27।-294, 2005.

TERNEU-ÉVRARD, J. L'Image de la femme dans le contexte de l'enseignement. In: RIGNAULT, S.; RICHERT, P. La Represéntation des hommes et des femmes dans les livres scolaires: Rapport au premier ministre. Paris: Centre de Documentation française, 1984. Disponível em: www.ladocumentationfrancaise.fr.rapportspublics/97407I -524/index. Acesso em: ago. 2008. 
TONINI, I. M. Identidades capturadas: gênero, geração e etnia na hierarquia territorial dos livros didáticos de geografia. Porto Alegre, 2002. Dissertação (mestr.) Universidade Federal do Rio Grande do Sul.

UMAÑA, S. A. El Género en la acción estatal de Costa Rica, una mirada desde las políticas educativas. In: STROMQUIST, N. P. L. (org.) La Construcción del género en las políticas públicas.Perú: IEP, 2006. p. 180.

UNICEF;UNIFEM. Manual de recomendaciones para la eliminación de estereotipos sexuales en los textos escolares y en los materiales educativos en general. Guatemala, 1990.

U'REN, M. B. The Image of woman in textbooks. In: GORNICK, V.; MORAN, B. K. (orgs.) Woman in sexist society: studies in power and powerlessness. New York: Signet Classics, Signette, Mentor and Plume Books, 1971. p.318-328.

VAL, M. da G. C.; CASTANHEIRA, M. L. Cidadania e ensino em livros didáticos de alfabetização e de língua portuguesa (de la a $4^{a}$ série). In: VAL, M. da G. C.; Marcuschi, B. (orgs.) Livros didáticos de português: letramento e cidadania. Belo Horizonte: Autêntica, 2005. p. | 47- 184.

VIANNA, C. P.; UNBEHAUM, S. O Gênero nas políticas públicas de educação no Brasil: 1988-2002. Cadernos de Pesquisa, v.34, n. 121 , p. 13-16, set./dez. 2004.

WEITZMAN, L. J. et al. Sex-role socialization in picture books for preschool children. American Journal of Sociology, n. 77, p. I. I25-1. 150, 1972.

ZIMET, S. G. Sex role models in primary reading texts of United States: 1600-1996. Denver, 1968. Thesis (Phd) University of Denver.

Recebido em: agosto 2008

Aprovado para publicação em: setembro 2008 